\title{
The Effects of N-(4-hydroxyphenyl) Retinamide on Proliferation and Apoptosis of Hela Cells
}

\author{
Xiao-Hong Han \\ School of Medical Science and Laboratory Medicine, Jiangsu University \\ 301 Xue Fu Road, Zhenjiang 212013, Jiangsu, China \\ Tel: 86-511-8503-0887 E-mail: hxh26160@163.com \\ Yan-Jun Xue (Equal contribution to the first author) \\ School of Medical Science and Laboratory Medicine, Jiangsu University \\ 301 Xue Fu Road, Zhenjiang 212013, Jiangsu, China \\ Tel: 86-511-8503-0887Ｅ-mail: xueyanjun7268@163.com \\ Shi-He Shao (Corresponding author) \\ School of Medical Science and Laboratory Medicine, Jiangsu University \\ 301 Xue Fu Road, Zhenjiang 212013, Jiangsu, China \\ Tel: 86-511-8503-8965-326 E-mail: Shaoshihe2006@163.com
}

\author{
Xian-Qian Li \\ Laboratory of Cancer, Putuo Hospital \\ 164 Lan Xi Road, Shanghai 200062, China \\ Tel: 86-21-6276-1578Ｅ-mail: xeexee@126.com
}

Hua-Xi Xu

Institute of Clinical Laboratory Medicine, Jiangsu University

301 Xue Fu Road, Zhenjiang 212013, Jiangsu, China

Tel: 86-511-8879-1048Ｅ-mail: xuhx@ujs.edu.cn

Received: April 29, 2011 Accepted: May 26, 2011 doi:10.5539/ijb.v3n3p161

\begin{abstract}
To investigate the effects of N-(4-hydroxyphenyl) retinamide (4HPR) on the proliferation and apoptosis of Hela cells, the cell growth was observed by SRB test, colony-forming test and nude mice carcinogenic test. Morphologic changes of apoptosis were observed under microscopes and the normal, apoptotic and necrotic cells were identified by fluorescence staining. The biochemical features and percentage of apoptosis were performed by flow cytometry (FCM) and DNA agarose gel electrophoresis. The results of SRB test, colony-forming test and nude mice carcinogenic test showed that 4HPR could inhibit the cells proliferation in vitro and in vivo $(\mathrm{P}<0.01)$. The apoptotic changes and apoptosis bodies could be observed under microscopes. The fluorescence staining revealed that 4HPR could induce the cells apoptosis, not necrosis. Typical DNA ladder appeared in 4HPR-treated cells and detected by FCM, the subdiploid nuclear peak appeared on the left of G1 peak and the apoptotic percentage was correlated with 4HPR in a dose and time dependent manner $(\mathrm{P}<0.01)$. All these results indicated that 4HPR could inhibit the proliferation of Hela cells and induce the cells apoptosis.
\end{abstract}

Keywords: N-(4-hydroxyphenyl) retinamide (4HPR), Hela cell, Proliferation, Apoptosis 


\section{Introduction}

4HPR is a synthetic retinoid that displays an important regulative effect on keeping cells normal growth, development and differentiation and has inhibitive effect on tumor's happening and development (Hail N Jr et al., 2001). Inducing tumor cells apoptosis is one of the mechanisms for many chemical medicines to inhibit the proliferation of tumor cells. Although advances have been made in clinical medicine, no effective treatment modality is available for patients with advanced or metastatic tumors. It had been demonstrated that 4HPR had obvious antitumor effects on bladder tumor (LIU Jia et al., 2005), human breast carcinoma cells, mice prostate cancer cells and ovarial cancer cells (Hail N Jr et al., 2001), but little is known about the effect of 4HPR on cervix carcinoma. Cervix carcinoma is a kind of common malignant tumors of female urogenital system and it's morbidity is the second of all of the female malignant tumors all of the world. Although we can treated it by operation, radiotherapy and so on, but chemotherapy is requisite as a kind of adjunctive therapy. Therefore, it is an attractive topic whether 4HPR is capable of preventing and treating cervix carcinoma. In this study we aims at detecting the effects of 4HPR on the proliferation of Hela cells in vitro and in vivo and apoptosis of Hela cells in vitro and bringing study and theory basis for cervix carcinoma treatment and preventation. Our results provided evidence that 4HPR could inhibit the Hela cells proliferation and induce it's apoptosis.

\section{Materials and Experiment Methods}

\subsection{Materials}

\subsubsection{Preparation of sample solution}

4HPR and Sulforhodamine B (SRB) were obtained from the professor Xian-Mao Luo (the Institute of oncology of the Chinese Vnim Medical College). The 4HPR powder 10mg was dissolved with 10mL Dimethyl sulfoxide (DMSO) to $10 \mathrm{mmol} / \mathrm{L} 4 \mathrm{HPR}$ solution and stored at $-20^{\circ} \mathrm{C}$. Then the $4 \mathrm{HPR}$ solution was added to the cell medium. The SRB was dissolved with $1 \%$ ethanoic acid to $0.4 \%(4 \mathrm{~g} / \mathrm{L}) \mathrm{SRB}$ solution.

\subsubsection{Animals and Cell lines}

Nude mice (Balb/c, seven-week old) were obtained from and breeded in the tumor Institute of the Chinese Vnim Medical College. Hela cell line was obtained from the Basic Institute of the Chinese Academy of Preventive Medicine.

\subsection{Experiment Methods}

\subsubsection{Cell culture}

The Hela cells were grown in culture at $37^{\circ} \mathrm{C}, 5 \% \mathrm{CO}_{2}$ in RPMI 1640 (Gibco, USA) supplemented with $10 \%$ fetal bovine serum (Beyotime Institute of Biotechnology, Shanghai, China). The culture medium was renewed every three or four days. Then 4HPR was applied to these cells (added to the media).

\subsubsection{Cell viability assay}

Measurement of the cells growth inhibition was carried out by SRB test. The Hela cells were added into 96-well plates (3000/well) and cultured for $24 \mathrm{~h}$ and then continued to be cultured for 24,48 and $72 \mathrm{~h}$ after treated with 4HPR (the final concentration was $1,2,4,8$ and $16 \mathrm{ug} / \mathrm{mL}$, respectively). When culture finished, the cells were fixed in $100 \mathrm{uL}$ TCA $(100 \mathrm{~g} / \mathrm{L})$ for $30 \mathrm{~min}$, washed four to five times with water, dried at room temperature and

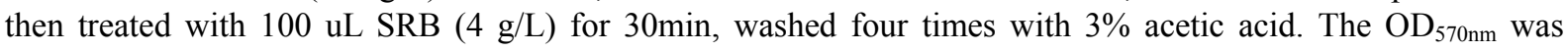
measured immediately after treated with $200 \mathrm{uL}$ Tris- $\mathrm{HCl}(10 \mathrm{mM})$ for $10 \mathrm{~min}$. Results were measured in triplicate. The cells inhibition rate was calculated according to the following formula: the inhibition rate $(\%)=$ $\left(1-\mathrm{OD}_{\text {treated }} 570 / \mathrm{OD}_{\text {control }} 570\right) \times 100 \%$. Based on the inhibition rates of each group of drugs on cells, SPSS software was used to calculate $50 \%$ inhibitory concentrations (IC50).

\subsubsection{Colony-forming test}

Cells were plated in $100 \mathrm{~mm}$ tissue culture dishes (1000/dish) and 4HPR (the final concentration was $8 \mu \mathrm{g} / \mathrm{mL}$ ) was added after $24 \mathrm{~h}$. Both the control group and the treated group were three dishes. Ten days later, colonies with a diameter of more than $0.5 \mathrm{~mm}$ were counted and photographed. Colony forming efficiency was calculated according to the following formula: colony forming efficiency $(\%)=$ colony number $\times 100 \% /$ cell number inoculated.

\subsubsection{Morphological changes}

2.2.4.1 Light microscope: The Hela cells which had been treated with 4HPR (the final concentration was 8 $\mu \mathrm{g} / \mathrm{mL}$ ) for $72 \mathrm{~h}$ were observed under a light microscope.

2.2.4.2 Electron microscope: The Hela cells were cultured with 4HPR (the final concentration was $8 \mu \mathrm{g} / \mathrm{mL}$ ) for 
$72 \mathrm{~h}$, then fixed with $2 \%$ paraformaldehyde / $2 \%$ glutaraldehyde in $0.1 \mathrm{~mol} / \mathrm{L}$ phosphate buffer $(\mathrm{pH} 7.4)$, followed by $1 \%$ osmium tetroxide. After dehydration, thin sections were stained with uranyl acetate and Lead citrate for observation under a JEM 2000 EX electronmicroscope (JEC, USA).

2.2.4.3 Fluorescent microscope: The Hela cells were treated with 4HPR (the final concentration was $8 \mu \mathrm{g} / \mathrm{mL}$ ) for $72 \mathrm{~h}$, washed twice with PBS, separated to single cell suspension, supplemented with $1 \mathrm{mg} / \mathrm{mL}$ Hoechst 33258 , water bath at $37^{\circ} \mathrm{C}$ for $7 \mathrm{~min}$, cooled on ice, centrifugated in order to wipe off the dye solution. The cells were resuspended in PBS, dyed evading light for $30 \mathrm{~min}$ with $5 \mathrm{ug} / \mathrm{mL}$ PI, then centrifugated again to release the dye solution and observated under a fluorescent microscope (Nikon eclipse TE300, JAPAN) after washed with PBS.

2.2.4.4 Laser focusing microscope: The Hela cells were treated with 4HPR (the final concentration was $8 \mu \mathrm{g} / \mathrm{mL}$ ) for $72 \mathrm{~h}$, fixed in $75 \%$ alcohol for $30 \mathrm{~min}$, washed twice with PBS, and then treated with $45 \mathrm{ug} / \mathrm{mL}$ RNase (Gibco, USA) for $40 \mathrm{~min}$ at $37^{\circ} \mathrm{C}$. The samples were observed under a laser focusing microscope (LSM 5 PASCAL, ZEISS, Germany) immediately.

\subsubsection{Identification of normal, apoptotic and necrotic cells by fluorescence staining}

Cells were seeded into $25 \mathrm{~mL}$ flasks $\left(8 \times 10^{4} / \mathrm{mL}\right.$ ) and 4 HPR (the final concentration was $8 \mu \mathrm{g} / \mathrm{mL}$ ) was added after $24 \mathrm{~h}$. The control group was given only culture medium containing no drugs. Each treatment was tested in tetrad flasks. All the above flasks were incubated for $72 \mathrm{~h}$. The following protocol was carried out as the Normal /Apoptotic/Necrotic cell Detection Kit (NANJING KEYGEN BIOTECH. CO., LTD) instruction book described. Cells were observed under a fluorescence microscope equipped with a $510 \mathrm{~nm}$ excitation filter and photos were taken (Nikon eclipse TE300 and Nikon Digital Sight, JAPAN). The cells apoptotic/ necrotic efficiency was calculated according to the following formula: cells apoptotic efficiency $(\%)=$ (nonage apoptotic cells + advanced stage apoptotic cells) $\times 100 \% /$ cell number; cells necrotic efficiency $(\%)=$ necrotic cells $\times 100 \% /$ cell number.

\subsubsection{DNA agarose gel electrophoresis}

The Hela cells were treated with 4HPR (the final concentration was $8 \mu \mathrm{g} / \mathrm{mL}$ ) for $72 \mathrm{~h}$, washed twice with PBS containing $2 \mathrm{mM}$ EDTA, then treated with $0.3 \mathrm{~mL}$ TEB (45 mM Tris-HCl PH 8.7, $1 \mathrm{mM}$ EDTA), $0.25 \%$ NP-40, RNase $(10 \mathrm{~g} / \mathrm{L})$ at $37^{\circ} \mathrm{C}$ for $40 \mathrm{~min}$. After treated with protease $\mathrm{K}(1 \mathrm{mg} / \mathrm{mL})$ at $37^{\circ} \mathrm{C}$ for $40 \mathrm{~min}, 45 \mathrm{uL}$ supernatant fluid was collected, then mixed with $25 \mathrm{uL}$ loading buffer, then electrophoresis in $15 \mathrm{~g} / \mathrm{L} \mathrm{DNA}$ agarose gel (supplemented with $0.5 \mathrm{mg} / \mathrm{mL} \mathrm{EB}$ ) for $2.5 \mathrm{~h}$, voltage $40 \mathrm{~V}$, and then observated under an ultraviolet lamp.

\subsubsection{FCM analysis}

Apoptotic feature, apoptotic percentage and the changes of Hela cells were determined by FCM according to the following protocol. The cells were treated with 4HPR (the final concentration was 1, 2, 4, 8 and $16 \mathrm{ug} / \mathrm{mL}$, respectively) for $24,48,72$ and $96 \mathrm{~h}$, respectively. The cells $\left(1 \times 10^{6}\right)$ were collected and then fixed in $70 \%$ alcohol at $4{ }^{\circ} \mathrm{C}$ overnight, then the cells were centrifugated for $5 \mathrm{~min}$ at $1000 \mathrm{rpm} / \mathrm{min}$. The supernatant was removed and the cells were washed twice with PBS. Then the cells were resuspended in $3 \mathrm{~mL}$ PBS and $3 \mathrm{~mL}$ phosphate-citrate buffer $\left(0.2 \mathrm{M} \mathrm{Na}_{2} \mathrm{HPO}_{4}\right.$ and $0.1 \mathrm{M}$ citric acid $)$ was added into the cells. After incubated for 30 min, the cells were collected and resuspended in $150 \mu \mathrm{L}$ PI $(10 \mathrm{ug} / \mathrm{mL})$ and $200 \mu \mathrm{L}$ RNase $\mathrm{A}(20 \mathrm{ug} / \mathrm{mL})$. The samples were incubated at room temperature in dark for $30 \mathrm{~min}$ and analyzed in triplicate by FCM (FACS 420, Becton Dickinson Co., USA). Cell populations in the sub-G1 area were quantified from a standard count of $10^{4}$ cells using MULTYCYCLE software (PHEONIX Co., USA).

\subsubsection{In vivo anti-tumor activity}

Ten seven-week old male nude mice were randomized into 2 groups (treated and control group, $n=5$ ). They were inoculated subcutaneously with transplanted Hela cells $\left(5 \times 10^{6}\right.$ cells per mouse). Mice in treated group were inoculated the cells treated by 4HPR (the final concentration was $8 \mu \mathrm{g} / \mathrm{mL}$ ) for $72 \mathrm{~h}$ beforhand, while mice in control group were inoculated the cells untreated. Seventeen days later, the animals were sacrificed and their tumors were removed and weighed immediately. Tumor inhibitory rate was calculated according to the following formula: tumor inhibitory rate $(\%)=(1-$ Wtreated $/$ Wcontrol $) \times 100 \%$.

\subsubsection{Statistical analysis}

Data were given as the means $\pm \mathrm{SD}$. Variance analysis between groups was performed by one-way ANOVA and significance of difference between control and treatment groups was analyzed using $t$-test. The differences with $\mathrm{p}$ $<0.05$ were considered statistically significant. 


\section{Results}

\subsection{Effects of 4HPR on Hela cells in vitro}

\subsubsection{SRB test result}

The result of SRB test showed that 4HPR could inhibit the proliferation of Hela cells in a time and dose-dependent manner $(\mathrm{P}<0.01)$ (Fig.1). The inhibition rates were $10.87 \%, 13.91 \%, 20.43 \%, 33.91 \%$ and $76.52 \%$, respectively after treated with 1, 2, 4, 8 and $16 \mu \mathrm{g} / \mathrm{mL} 4 \mathrm{HPR}$ for $72 \mathrm{~h}$. The IC50 of 4HPR for Hela cells was $10.28 \mu \mathrm{g} / \mathrm{ml}$.

\subsubsection{Colony-forming test result}

Fig.2 showed the cells colony-forming after the treatment with 4HPR for 10 days. With our nude eyes we could find that the control group had many colony-forming and the 4HPR group had very little colony-forming. Under microscope we could observe that: the control group- the shapes of the colonies were in order, the morphous of the cells were good and the disposition between the cells was tight; the 4HPR group- the shapes of the colonies were in disorder, the cells number of the colony was few, the cells adherence to the wall of the flasks were untight, the morphous of the cells were bad and the disposition between the cells was very loose. The colony forming efficiency (\%) of control group and 4HPR-treated group was $(38.2 \pm 1.0) \%$ and $(7.0 \pm 0.7) \%$, respectively $(\mathrm{P}<0.01)$.

\subsubsection{Morphological changes}

When treated with 4HPR for $72 \mathrm{~h}$, the cells had obvious morphological changes: under light microscope- some cells became round, blunt and shrinkage, smaller in size, membrane blebbing, holes, cytoplasmic extrusions, formation of apoptotic bodies, cells became detached and suspended in the medium (Fig.3); under electron microscope- nuclear pycnosis, nuclear membrance twist, nuclear chromosome assembled to lump and close to membrance (Fig.4); under laser focusing microscope- nuclear chromosome pycnosis, aggregated and close to edge (Fig.5); under fluorescent microscope- dyed with Hoechst 33258-PI, the vital cells and apoptosis cells were blue and the dead cells were red, the apoptotic bodies could be seen (Fig.6).

\subsubsection{Identification of normal, apoptotic and necrotic cell by fluorescence staining}

The results of fluorescence staining revealed that when treated with 4HPR for 72h, some apoptotic cells could be seen under fluorescent microscopy. The nonage apoptotic cells (green nucleoid, irregular cells, eg. crescent-shaped) and advanced stage apoptotic cells (orange nucleoid, chromosome condensation, nuclear fragmentation, vary size) were visible. But necrotic cells were not found (oval cells, uniform orange yellow nucleoid, regular cells). Otherwise, in control group, the cells were regular in morphology, cells were round and nucleoid were uniform green. But apoptotic and necrotic cells were seldom found. The cells apoptotic efficiency (\%) of control group and 4HPR-treated group was $0.432 \% \pm 0.834 \%$ and $32.931 \% \pm 1.213 \%$, respectively $(\mathrm{P}<0.01)$.

\subsubsection{DNA ladder result}

The result of DNA Ladder indicated that the DNA of Hela cells which had been treated by $8 \mathrm{ug} / \mathrm{mL} 4 \mathrm{HPR}$ for $72 \mathrm{~h}$ ruptured and typical DNA ladder appeared in $15 \mathrm{~g} / \mathrm{L}$ DNA agarose gel electrophoresis (Fig. 7).

\subsubsection{FCM result}

FCM with only PI staining showed that cells treated with 4HPR, the subdiploid nuclear peak appeared on the left of G1 peak (Fig. 8). As shown in Fig.9, FCM analysis also revealed the effect of 4HPR on the induction of apoptosis was in a dose and time-dependent manner $(\mathrm{P}<0.01)$ (Fig. 9).

\subsection{Effect of 4HPR on inoculated tumors in mice}

The lumps could be touched at the sites where the un-treated cells were inoculated at the third day, while the lumps could be touched at the sites where the 4HPR-treated cells were inoculated at the sixth day. Furthermore, the volumes of the latter were smaller than the former obviously. The mice were sacrificed at the $17^{\text {th }}$ day and the tumour tissues were separated. The tumours were irregular, solid and there were no metastasis. The average weight of the tumours $(\bar{X} \pm S D, n=5)$ : the control group was $(0.485 \pm 0.064)$ g and the 4HPR group was $(0.133 \pm 0.014)$ g. The result indicated that 4 HPR could inhibit the growth of Hela cells in vivo $(\mathrm{P}<0.01)$. The tumor inhibitory rate was $72.58 \%$.

\section{Discussion}

4HPR is a kind of artificial-synthetic analogue of vitamin A and belongs to retinoids. It could inhibit the proliferation of human breast carcinoma cells, mice prostate cancer cells and ovarial cancer cells (Hail $\mathrm{N} \mathrm{Jr}$ et al., 
2001). 4HPR aggregated mainly in fat tissue of mammary cancer and didn't deposit in liver, so 4HPR had lower toxicity on liver. The results of cytotoxicity and animal research indicated that 4HPR had antitumor activity and the activity had a lot of properties: such as extensive, low toxic, low side effect and high efficiency, and so on (Dipietrantonio AM et al., 2000; Asumendi A et al., 2002; Formellif et al., 1993). In the Phase II trial that carried out in American, the researchers had found that 4HPR had significant anti-cancer effect and had no obvious toxic and side-effect when it was long-term utilized (Takahashi $\mathrm{N}$ et al., 2002). Furthermore the side-effect of 4HPR was less than vitamin A. So 4HPR was an anti-cancer drug that had a good promising.

Cervix carcinoma is a kind of usual malignant tumours of female urogenital system and it's morbidity is the second of all of the female malignant tumours all of the world and it's mortality is the third of female tumours of Chinese. Though the cervix carcinoma could be treated by operation, radiation therapy, etc. But chemotherapy was indispensable as a supportive therapy.

SRB test was often adopted to evaluate the growth inhibitory effects of anti-cancer drugs on short-term cultured tumour cells and was more sensitive than MTT assay. Colony-forming test was one of the precise-indexes that could test if the cultured cells could proliferate and it was more accurate than growth curve, furthermore it was applied to evaluate the inhibited effect of anti-cancers. In this study, the result of SRB test showed that 4HPR could inhibit the proliferation of Hela cells in a time and dose-dependent manner $(\mathrm{P}<0.01)$ and the IC50 was $10.28 \mu \mathrm{g} / \mathrm{ml}$. The colony-forming test showed that 4HPR could inhibit the proliferation of Hela cells $(\mathrm{P}<0.01)$. All these results indicated that 4HPR could inhibit the proliferation of Hela cells in vitro. At the same time, the nude mice carcinogenic test showed that 4HPR could inhibit the growth of Hela cells in the mice $(\mathrm{P}<0.01)$. In a word, 4HPR could inhibit the proliferation of Hela cells both in vivo and in vitro.

Inducing cells apoptosis was one of the mechanisms for many chemical drugs to anti-tumor. 4HPR was different from RA (retinoic acid) and it wasn't restrained by RAR (Retinoic receptor) Preparation receptor channel. The anti-tumour activity of 4HPR was concerned with 4HPR-induced apoptosis (Shimada K et al., 2003). 4HPR could inhibit the proliferation and induce the apoptosis of human bile duct cancer cells QBC939 (LUO Kunlun et al., 2004). However, the induction of apoptosis and anti-tumour activity of 4HPR in Hela cells hadn't been reported.

Apoptosis (APO) is a kind of cell's physiological death and is characterized by its specific morphological and biochemical features. The morphological changes of apoptosis usually involves: cells shrinkage, cytoplasm pycnosis, karyosome disappearance, the nuclear chromatin condensation and aggregates peripherally under the nuclear membrane and well-delimited masses of various shapes and sizes, nuclear membrane twisting, sometimes "crescent cap" formation, and in the end the apoptotic bodies development. The fragmented "apoptic bodies" are phagocytosed quickly by macrophages and other epithelia cells adjacent. Moreover, apoptosis does not elicit an inflammatory response and apoptosis is a relatively distinctive and important mode of cell death that is differentiated from necrosis. The biochemical feature of apoptosis is reflected by peculiar fragmentation of DNA (180-200bp discontinuous polyploidy DNA chains) and there are typical DNA ladder appearing in DNA agarose gel electrophoresis. In 1980, Langlosis firstly reported to analyze the chromosome of the apoptosis cells by FCM and the subdiploid nuclear peak appeared on the left of G1 peak.

In this study, apoptosis of Hela cells induced by 4HPR were detected by light, laser focusing, fluorescent, electron microscopes, DNA agarose gel electrophoresis and FCM. It was found that Hela cells had obvious apoptosis morphological changes under laser focusing and electron microscopes and apoptosis bodies could be found under light and fluorescent microscopes. Furthermore, the fluorescence staining revealed that 4HPR could induce the cells apoptosis, not necrosis. Typical DNA ladder appeared in 4HPR-treated cells in DNA agarose gel electrophoresis. Detected by FCM, subdiploid nuclear peak appeared on the left of G1 peak and diploid cells peak reduced. FCM analysis also revealed the effect of 4HPR on the induction of apoptosis was in a dose and time-dependent manner $(\mathrm{P}<0.01)$.

The study pointed out that 4HPR could inhibit the proliferation of Hela cells by induction of cells apoptosis and it was the same as Wai-Lung Lai's report (Wai-Lung Laia et al.,2008). Taken together, our study had demonstrated that 4HPR could inhibit Hela cells proliferation and induce the cells apoptosis in vitro. Significant anti-tumor effects of 4HPR could also be observed in the Hela tumor xenograft model of nude mice.

In recent years, several pathways leading to caspase activation and apoptosis have been elucidated, including pathways triggered by: the extrinsic (Fas death receptor- mediated) pathway, mitochondrion pathway and endoplasmic reticulum (ER) pathway (E.J.Choi et al., 2009; Han-Jung Chae et al., 2004). For zooblast, the mitochondrion pathway is not only the most general apoptosis mechanism but also the core of cells apoptosis (Sheng X et al., 2008). Some stress signals intracellular can lead to mitochondrial outer membrane permeability 
(MOMP)increasing (Kirkegaard T., 2009) and then MOMP-increasing results in the mitochondrial membrane potential $(\Delta \Psi \mathrm{m})$ decreasing, cytc and some apoptosis inducing factors (AIF) releasing from mitochondria (De Bruin EC et al., 2008). Cytc binds to and induces oligomerization of Apaf-1, then procaspase-9 is recruited and autoactivated. Activated caspase-9 cleaves and activates effector caspases such as caspase-3, caspase-7 and caspase-8, then cleave a variety of cellular proteins and cause cell death (Tsujimoto Y, 2002; Nutku E et al., 2005). A key step in the intrinsic mitochondrial apoptotic pathway is the releasing of cytc from the mitochondria to activate Apaf- 1 , which turns on the caspase cascade. The release of cytc from mitochondria is usually preceded or accompanied by a reduction of $\Delta \Psi \mathrm{m}$ and caspase-9 and Apafl play a central role in the caspase cascade which is responsible for the mitochondria apoptotic process. Disruption in $\mathrm{Ca}^{2+}$ homeostasis, inhibition of protein glycosylation and accumulation of misfolding proteins may both induce ER stress which is associated with a range of diseases. Normally, the unfolded protein response (UPR) is activated to protect cells that are experiencing ER stress. However, sustained or intense ER stress can lead to apoptosis (Szegezdi E et al., 2003). The Caspase-12 pathways mechanism of apoptosis induced by ER-pathway demonstrated that ER stress-induced apoptosis can be mediated through the activation of caspase- 12 which is localized to the outer membrane of the ER. The activation of caspase-12 eventually leads to activation of caspase-3/7 and apoptosis (Rao RV et al., 2001). In the mitochondrial pathway, death signals induce the opening of mitochondrial permeability transition pores, which cause mitochondrial-membrane depolarization and the release of apoptosis inducing proteins. In some instances, both pathways may work synergistically. Recent studies found that lysosome has an important effect on apoptosis pathway (Marianela C et al., 2009). But as we know that the different apoptosis pathways were not isolated, but intercommunication and they developed into a complex network, that was named "cross talk" ( Basu S et al., 2009; Kandasamy K et al., 2003; Nutt LK et al., 2002). So next step, we will go on to study the mechanism of it's apoptosis mainly on mitochondrion and ER pathway and the relationship between different apoptosis pathways will be studied too.

\section{Acknowledgements}

The authors would like to be grateful to prof. Shi-He Shao for her excellent technical support.

\section{References}

Asumendi A, Morales MC, Alvarez A, et al. (2002). Implication of mitochondria-derived ROS and cardiolipin peroxidation in N-(4-hydroxyphenyl) retinamide-induced apoptosis. $\mathrm{Br} J$ Cancer, 86 (12):1951-1956. doi:10.1038/sj.bjc.6600356, http://dx.doi.org/10.1038/sj.bjc.6600356

Basu S, Harfouche R, et al. (2009). Nanoparticle-mediated targeting of MAPK signaling predisposes tumor to chemotherapy. Proc Natl Acad Sci USA, 106 (19):7957-7961. doi:10.1073/pnas.0902857106, http://dx.doi.org/10.1073/pnas.0902857106

De Bruin EC, Medema JP. (2008). Apoptosis and non-apoptotic deaths in cancer development and treatment response. Cancer Treat Rev, 34: 737-749. doi:10.1016/j.ctrv.2008.07.001, http://dx.doi.org/10.1016/j.ctrv.2008.07.001

Dipietrantonio AM, Hsieh TC, Juan G, et al. (2000). Fenretinide-induced caspase 3 activity involves increased protein stability in a mechanism distinct from reactive oxygen species elevation. Cancer Res, 60(16) :4331-4335.

E.J.Choi, W.S.Ahn, et al. (2009). Equol induces apoptosis through cytochrome c-mediated caspases cascade in human breast cancer MDA-MB-453 cells, Chemico. Biological Interactions, 177: 7-11. doi:10.1016/j.cbi.2008.09.031, http://dx.doi.org/10.1016/j.cbi.2008.09.031

Formellif, Clericim, Campatetal. (1993). Five yearad ministration offenretinide pharma cokineticsand effects on plasma retnol concentration. J Clin Oncol, 11(10):2036-2042.

Hail N Jr, Lotan R. (2001). Mitochondrial respiration is uniquely associated with the prooxidant and apoptotic effects of N-(4-hydroxyphenyl) retinamide. J Biol Chem, 276 (49): 45614-21. doi:10.1074/jbc.M106559200, http://dx.doi.org/10.1074/jbc.M106559200

Han-Jung Chae, Sun-Kyung Yang, et al. (2004). Ge-Jee-Bok-Ryung-Hwan induces apoptosis in humancervical carcinoma HeLa cells-An endoplasmic reticulum stress pathway. Life Sciences, 75: 2997-3016. doi:10.1016/S0024-3205(04)00752-0, http://dx.doi.org/10.1016/S0024-3205(04)00752-0

Kandasamy K,Srinivasula SM, et al. (2003). Involvement of proapoptotic molecules Bax and Bak in tumor necrosis factor-related apoptosis-inducing ligand (TRAIL)-induced mitochondrial disruption and apoptosis: differential regulation of cytochrome $\mathrm{c}$ and Smac/DIABLO release. Cancer Res, 63(7):1712-1721.

Kirkegaard T, Jäättelä M. (2009). Lysosomal involvement in cell death and cancer. Biochim Biophys Acta,1793: 
746-754. doi:10.1016/j.bbamcr.2008.09.008,http://dx.doi.org/10.1016/j.bbamcr.2008.09.008

LIU Jia, LI Ai-ping, LI Chun-ping, et al. (2005). The role of reactive oxygen species in N-[4-hydroxyphenyl] retinamide induced apoptosis in bladder cancer cell lineT24. Chinese Journal of Industrial Hygiene and Occupational Diseases, 23(3):191-194.

LUO Kunlun, XU Xiaojun, HE Zhenping, et al. (2004). Induction of cell-cycle arrest and apoptosis by 4HPR in human cholangiocarcinoma cells and its possible mechanism. Chin J Hepatobiliary Surg, 10(2):111-114.

Marianela C. Serradell, Lorena G, et al. (2009). Involvement of a mitochondrial pathway and key role of hydrogen peroxide during eosinophil apoptosis induced by excretory-secretory products from Fasciola hepatica. Molecular \& Biochemical Parasitology, 163: 95-106. doi:10.1016/j.molbiopara.2008.10.005, http://dx.doi.org/10.1016/j.molbiopara.2008.10.005

Nutku E, Hudson SA, et al. (2005). Mechanism of Siglec-8-induced human eosinophil apoptosis: role of caspases and mitochondrial injury. Biochem Biophys Res Commun, 336: 918-924. doi:10.1016/j.bbrc.2005.08.202, http://dx.doi.org/10.1016/j.bbrc.2005.08.202

Nutt LK, Pataer A, et al. (2002). Bax and Bak promote apoptosis by modulating endoplasmic reticular and mitochondrial Ca2+ stores. J Biol Chem,277(11):9219-9225. doi:10.1074/jbc.M106817200, http://dx.doi.org/10.1074/jbc.M106817200

Rao RV, Hermel E,Castro-Obregon S et al. (2001). Coupling endoplasmic reticulum stress to the cell death program. Mechanism of caspase activation. J Biol Chem, 276:33869-33874. doi:10.1074/jbc.M102225200, http://dx.doi.org/10.1074/jbc.M102225200

Sheng X, Sun Y, et al. (2008). Cirsilineol inhibits proliferation of cancer cells by inducing apoptosis via mitochondrial pathway. The journal of pharmacy and pharmacology, 60:1523-1529. doi:10.1211/jpp.60.11.0014, http://dx.doi.org/10.1211/jpp.60.11.0014

Shimada K, Nakamura M, Isida E, et al. (2003). Requirement of c-jun for testosterone-induced sensitization to N-(4-hydroxyphenyl) retinamide-induced apoptosis. Molecular Carcinogenesis, 36:115-122. doi:10.1002/mc.10107, http://dx.doi.org/10.1002/mc.10107

Szegezdi E, Fitzgerald U, Samali A. (2003). Caspase-12 and ER-stress-mediated apoptosis: the story so far. Ann N Y Acad Sic, 1010: 186-194. doi:10.1196/annals.1299.032, http://dx.doi.org/10.1196/annals.1299.032

Takahashi N, Ohba T, Togashi S, et al. (2002). Biological activity of p-methylaminophenol, an essential structural component of N-(4-Hy-droxyphenyl) retinamide, fenretinide. J Biochem, 132:767-774.

Tsujimoto Y. (2002). Bcl-2 family of proteins: life-or-death switch in mitochondria. Biosci Rep, 22: 47-58. doi:10.1023/A:1016061006256, http://dx.doi.org/10.1023/A:1016061006256

Wai-Lung Laia, Nai-Sum Wong. (2008). The PERK/eIF2 $\alpha$ signaling pathway of Unfolded Protein Response is essential for N-(4-hydroxyphenyl) retinamide (4HPR)-induced cytotoxicity in cancer cells. Experimental Cell Research, 314:1667-1682. doi:10.1016/j.yexcr.2008.02.002, http://dx.doi.org/10.1016/j.yexcr.2008.02.002 


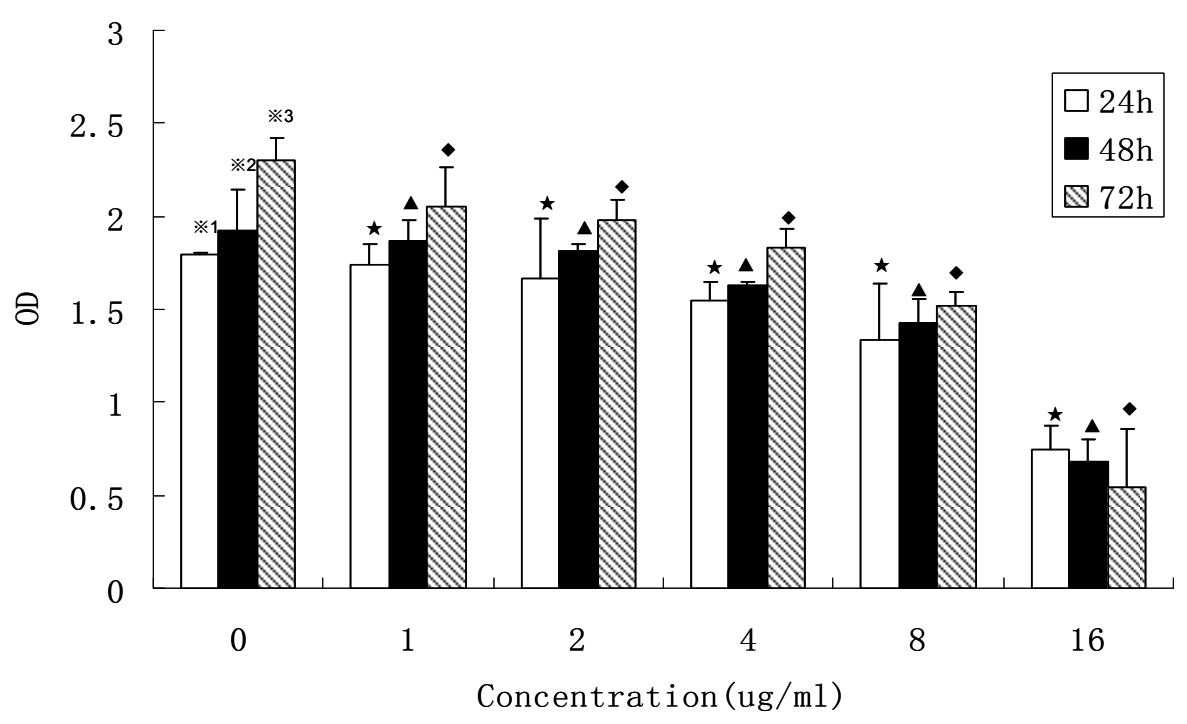

Figure 1. Effect of 4HPR on the OD of Hela cells

$\star$ vs $※ 1, \Delta$ vs $※ 2, \diamond$ vs $※ 3 \mathrm{P}<0.01$ illustrated that 4 HPR could inhibit the proliferation of Hela cells.

$\star v \mathrm{v} \Delta, \star \mathrm{vs} \diamond, \nabla \mathrm{vs} \Delta \mathrm{P} \mathrm{P}<0.01$ illustrated that the degree of inhibition was positively correlated to the time of the action of 4HPR at one certain concentration. $\mathrm{P}<0.01$ between different $4 \mathrm{HPR}$-concentration groups at one certain time illustrated that the degree of inhibition was positively correlated to the concentration of 4HPR
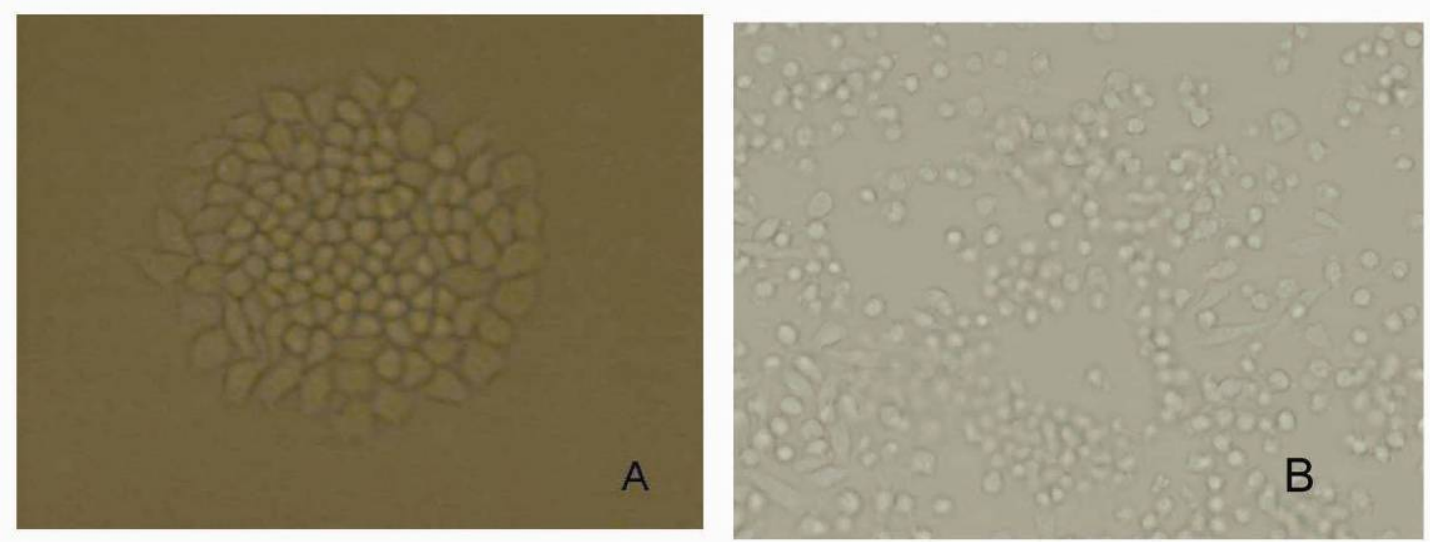

Figure 2. Colony-forming of Hela cells. 200×(A:Control group, B: 4HPR group)

The control group: the shapes of the colonies were in order, the morphous of the cells were good and the disposition between the cells were tight; the 4HPR group: the shapes of the colonies were in disorder, the cells number of the colonies was few, the cells adherence to the wall of the flasks were untight, the morphous of the cells were bad and the disposition between the cells were very loose. 

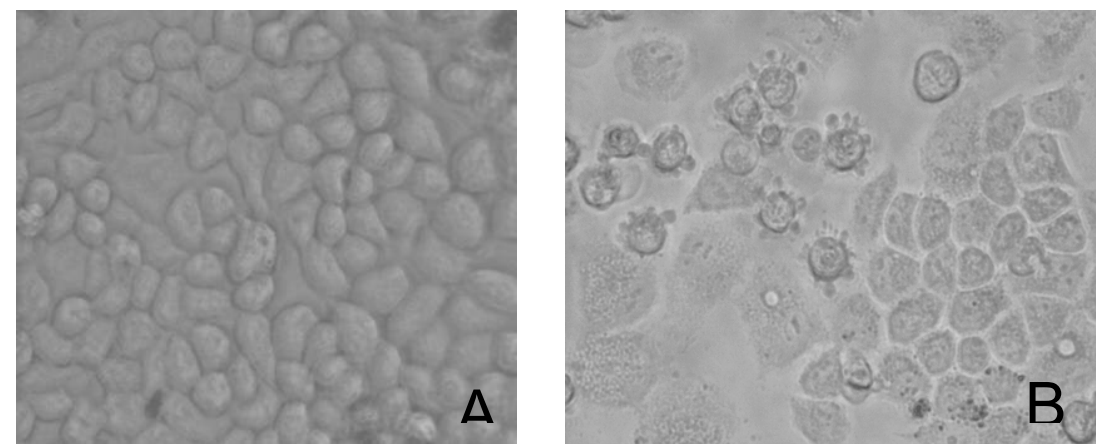

Figure 3. Hela cells exposed to 4HPR for 72h observed under light microscope. 400× (A: Control group, B:4HPR group)

The control group: the morphous of the cells were good and the disposition between the cells were tight; the 4HPR group: some cells became round, blunt and shrinkage, smaller in size, membrane blebbing, holes, cytoplasmic extrusions, formation of apoptotic bodies, cells became detached and suspended in the medium
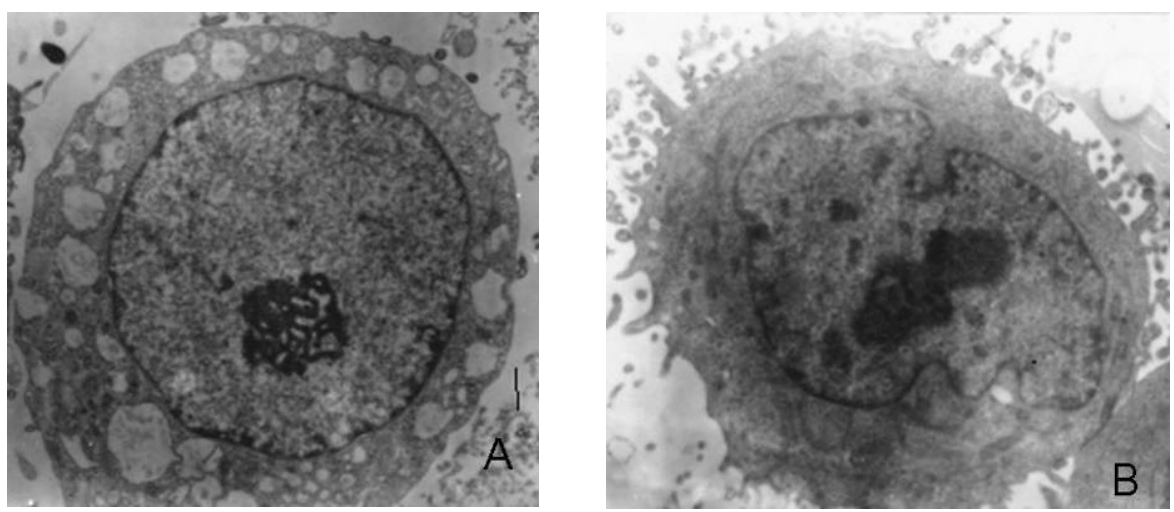

Figure 4. Hela cells exposed to 4HPR for 72h observed under electron microscope. 6000× ( A: Control group, $\mathrm{B}: 4$ HPR group)

4HPR group: nuclear pycnosis, nuclear membrance twist, nuclear chromomocre assembled to lump and close to membrance.
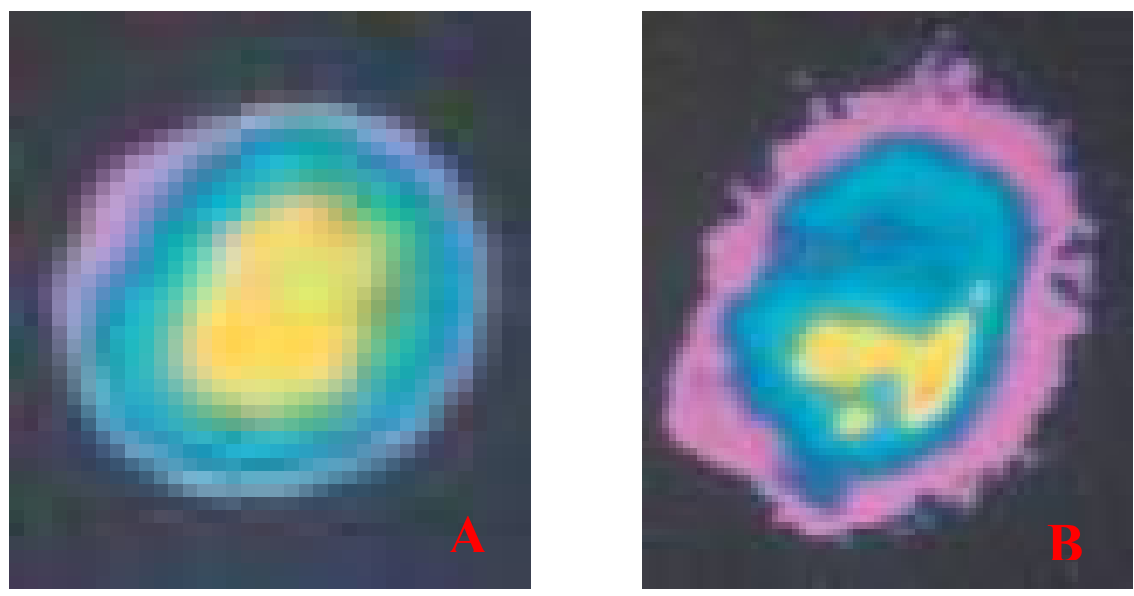

Figure 5. Hela cells exposed to 4HPR for $72 \mathrm{~h}$ observed under laser focusing microscope. $6000 \times($ A: Control group, B:4HPR group)

4HPR group : nuclear chromosome pycnosis, asserbled and close to edge. 

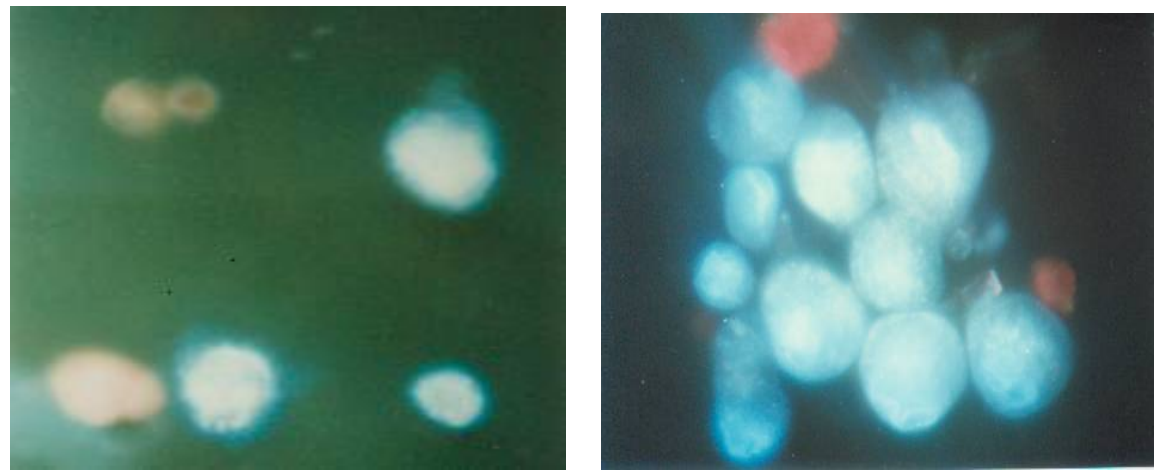

Figure 6. Hela cells under fluorescent microscope (red: dead cells, blue: vital cells and apoptosis cells) The vital cells and apoptosis cells were blue and the dead cells were red, the apoptotic bodies could be seen.

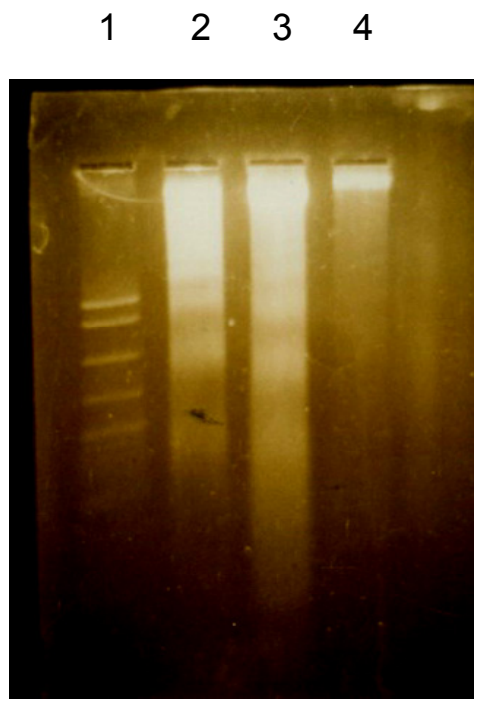

Figure 7. The Biochemical Feature of Cell Apoptosis-DNA Ladder(1: Mark, 3: 4HPR group, 4: control group)
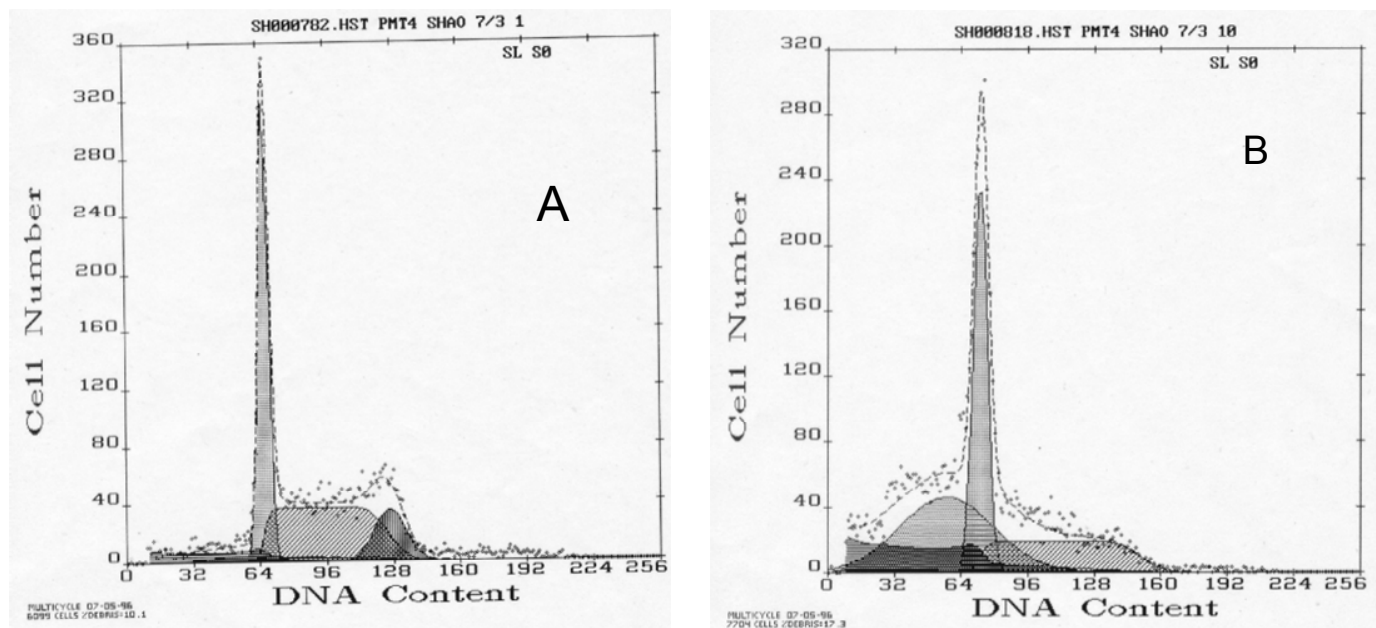

Figure 8. Limited chart of APO Hela cells detected by Flow Cytometry Analysis(A: control group, B:4HPR group)

4HPR group: the subdiploid nuclear peak appeared on the left of G1 peak 


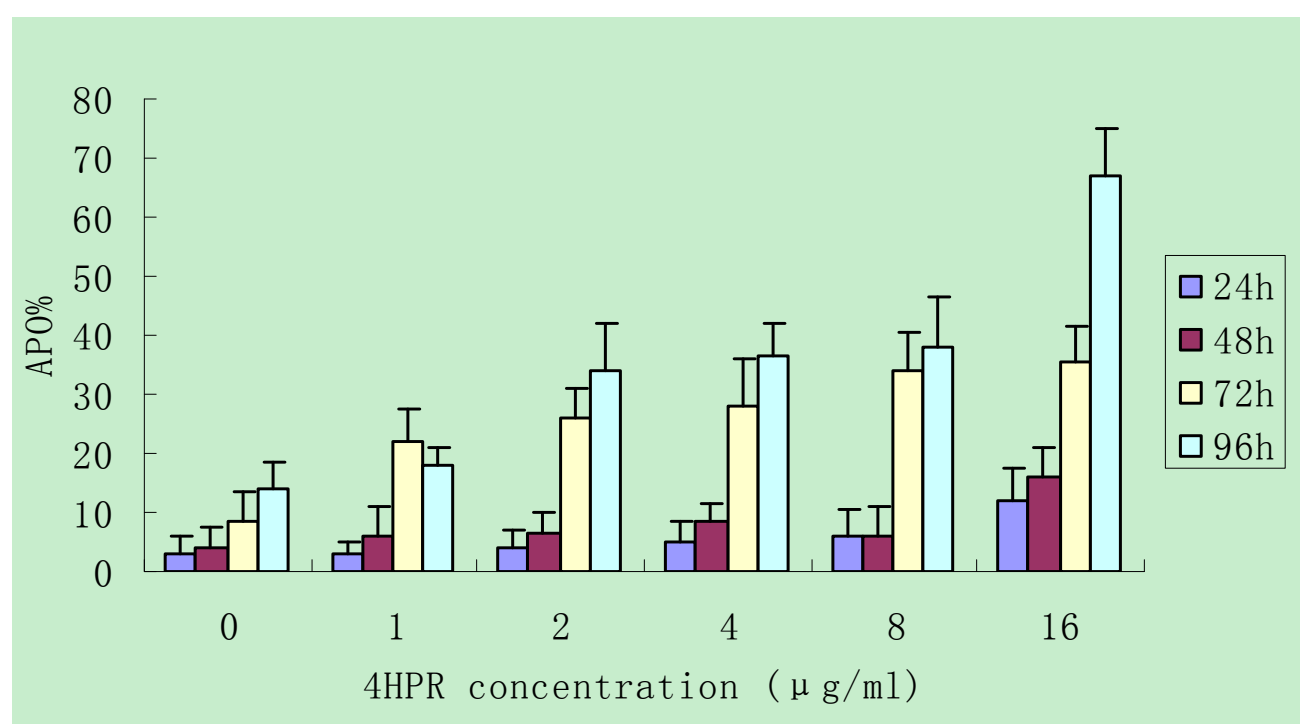

Figure 9. Effect of 4HPR on the APO\% of Hella cells

The 4HPR group vs the control group $(0 \mu \mathrm{g} / \mathrm{ml}$ group $) \mathrm{P}<0.01$ illustrated that $4 \mathrm{HPR}$ could induce the Hela cells apoptosis. The Probabilities between different treated -concentration groups at the same time were less than $0.01(\mathrm{P}<0.01)$ and the Probabilities between different treated-time groups at the same concentration were less than $0.01(\mathrm{P}<0.01)$ illustrated that the effect of $4 \mathrm{HPR}$ on the induction of apoptosis was in a dose and time -dependent manner. 